\title{
Investigation of the economical and technical design feasibility of Si-Fe graded distribution transformers according to EN50588-1
}

\section{EN50588-1'e uygun Si-Fe nüveli dağitim transformatörü tasariminin ekonomik ve teknik açidan değerlendirilmesi}

\author{
Mehmet Aytaç CINAR ${ }^{*}$ iD \\ ${ }^{1}$ Deparment of Technical Programmes, Izmit Vocational School, Kocaeli University, Kocaeli, Turkey. \\ aytac@kocaeli.edu.tr
}

\begin{abstract}
Medium power transformers are responsible of the great part of total power losses in the grid. With EN50588-1 regulation, no-load and load losses have strictly classified fotr high-efficient transformer designs. Manufacturers are currently focusing on obtaining the most efficient design with minimum cost. In this paper, manufacturing feasibilities of Si-Fe graded distribution transformers, considering the requirements of EN50588-1 regulation, are investigated. Eleven different steel types in three grades are evaluated using twenty different electrical designs. A prototype transformer was both simulated and experimentally tested to verify the results of design studies. Obtained results show that the manufacturing of $A_{0}$ and $A A_{0}$ class transformers are feasible using Si-Fe grades with suitable manufacturing methods. However, amorphous materials seem to be a mandatory choice for $A A A_{0}$ class transformers in technical manner.
\end{abstract}

Keywords: Transformer, Design, Manufacturing feasibility, Si-Fe grades, EN50588-1.

\section{Introduction}

Distribution transformers are the second largest loss-making component in electric power grid. Even if they operate with 98$99 \%$ efficiency, they are responsible of one third of the total power loss in European transmission and distribution grid, due to reached high power level and huge number of transformers installed in grid. That makes transformers one of the important fields of energy efficiency studies.

Requirements, related to electrical characteristics and design of medium power transformers, are set up by the European Standard EN50588-1, which was firstly published in 2015 and revised in 2017. With this standard, maximum no-load losses, load losses and noise levels of transformers are given and classified, depending on the rated power.

All loss causing factors should be carefully defined and minimized for the suitable design of transformers which correspond to the necessities of EN50588-1 regulation, by manufacturers. No-load losses could be mainly reduced by selecting better quality grades for core manufacturing. Improving core design and core manufacturing methods, such as cutting, fabrication and assembling are also helped to reduce

\section{Öz}

Dağıtım transformatörlerinde meydana gelen güç kayıpları elektrik sebekesindeki toplam kayıpların büyük kısmını olusturmaktadır. EN50588-1 standardı ile yüksek verimli transformatörlerde izin verilen en yüksek boșta ve yükte güç kayıpları yeniden düzenlenmiștir. Elektriksel kısitlara ek olarak, transformatör üreticileri için maliyet parametresi önemli de bir kriter olmaktadır. Bu çalıșmada, EN50588-1 standardında belirtilen kayıp sınıflarındaki dağıtım transformatörlerinin Si-Fe nüve malzemeleri ile üretim imkanı Teknik ve ekonomik yönden değerlendirilmektedir. Bu amaçla, üc ayrı sinıftakı onbir farklı Si-Fe nüve malzemesi kullanılarak yirmi farklı elektriksel tasarım gerçeklestirilmis olup, bu tasarımların üretilebilirliği teknik ve ekonomik açıdan değerlendirilmiștir. Elde edilen sonuçlar, uygun üretim yöntemleri ile $A_{0}$ ve $A A_{0}$ kayıp sinıflarındaki transformatörlerin Si-Fe malzemeler ile üretilebileceğini, fakat AAAo kayıp sınıfındaki dağıtım transformatörü üretimi için amorf malzeme kullanımının zorunlu olduğunu ortaya koymaktadır.

Anahtar kelimeler: Transformatör, Tasarım, Üretilebilirlik, Si-Fe malzeme, EN50588-1.

core losses. In other words, reducing load losses could be succeeded by using lower resistance material, increasing the cross section of the conductors and minimizing the other load loss components, such as stray losses.

There are many papers which investigate the effects of different core grades on no-load losses, in literature. In these studies, role of core grades on the efficiency of the transformer, was proven. Results of these studies show that the core losses could be reduced up to $35 \%$, by selecting thinner steel laminations and laser scribed grades [1]-[5].

Today, amorphous materials provide important advantages for high-efficient transformer manufacturing. Using low-loss, high permeability amorphous materials, the no-load losses of transformers are reduced up to $60-70 \%$ and increased transformer efficiency up to $99.7 \%$, compared to grain-oriented silicon steel transformers [6]-[9]. However, due to the saturated flux density and lamination factor values are lower than those of a grain-oriented core, necessity of additional structure to support core weight makes amorphous cores physically larger and vulnerable, especially for high power levels [10]. To avoid, the disadvantages of amorphous materials, such as higher cost and supply problems, combining

\footnotetext{
${ }^{*}$ Corresponding author/Yazıșılan Yazar
} 
grain-oriented silicon steel grades are also considered by the manufacturers. In [11]-[14], losses, total cost and temperature distributions of transformer cores are investigated, by considering the combinations of different steel grades in core design.

Core construction also deeply affects total core losses. Wound cores are important alternatives for reducing core losses. In [15], it was expressed that core losses could be decreased up to $15 \%$, compared to stacked cores. In [16]-[17], three phase five legged transformers with mixed $\mathrm{Si}-\mathrm{Fe}$ wound cores, are experimented. In larger transformers, stacked cores are more common, whereas in small and medium transformers, wound cores predominate. Using octagonal shaped wound cores, producing distribution transformers up to 5MVA, with reduced losses and manufacturing costs, is possible [18].

The purpose of this study is to investigate the various electrical designs of distribution transformers, which match EN50588-1 requirements in both technical and economical manner, using Si-Fe grades.

In Section 2, calculation of core losses is given, in detail. Section 3 expresses investigated core designs and effects of core materials on core losses. Electrical parameters of $1250 \mathrm{kVA}$, three-phase, $34.5 / 0.4 \mathrm{kV}, 50 \mathrm{~Hz}$ were considered as reference values for all design studies. Multi step-lap stacked core construction was applied and $\mathrm{V} /$ turn value was kept constant in design stages. Totally three grades and 11 different steel types were considered. 25 core induction values, between $0.25 \mathrm{~T}$ and $1.90 \mathrm{~T}$ were investigated to match the necessities of different core loss classes given in EN50588-1. Winding constructions were also optimized for each design, to agree load losses and short circuit reactance with the EN50588-1 requirements. In Section 4, experimental verification studies and obtained results are given. In Section 5, cost analyses and comparison studies are summarized. Output parameters of each design were used to calculate manufacturing costs. Finally, obtained results were commented by means of technical and economic feasibility.

\section{Calculation of core losses}

Relationship between main design parameters of a transformer is given as;

$$
E=4.44 N B_{m} f A
$$

where; $B_{m}$ is the maximum flux density, $N$ is the number of turns, $f$ is the frequency, $A$ is the core cross section area, respectively. According to the equation, core cross section and flux density are inversely proportional parameters, when the number of turns kept constant.

General specific core loss equation is given as;

$$
P_{\text {total }}=P_{h}+P_{e}+P_{i}
$$

under sinusoidal excitation. The three terms on the right side of the equation are hysteresis loss, classical eddy current loss and excess loss components, respectively. These components are mainly expressed as a function of induction and frequency, as;

$$
\begin{gathered}
P_{h}=k_{h} f B^{n} \\
P_{e}=k_{e} f^{2} B^{2} \\
P_{i}=k_{i} f^{1.5} B^{1.5}
\end{gathered}
$$

Where; $k_{h}$ is hysteresis loss coefficient, $k_{e}$ is eddy current loss coefficient and $k_{i}$ is excess loss coefficient, respectively. In addition, $n$ is called as Steinmetz coefficient and varies between 1.6 and 2, in literature. Literature studies show that, $1 \%$ rise of B causes a $2 \%$ rise of the losses [19].

Hysteresis, classical eddy current and excess loss coefficients are expressed as;

$$
\begin{gathered}
k_{h}=\frac{\pi}{\rho} \frac{H_{i r r}}{B_{p}} \\
k_{e}=\frac{\pi^{2} \sigma d^{2}}{6 \rho} \\
k_{i}=7.87 \sqrt{\sigma G V_{0} S}
\end{gathered}
$$

respectively [20]-[22]. In these equations; $H_{i r r}$ is the positive field strength value which correspond to the $\mathrm{B}=0$ point of the hysteresis curve of the material, $\sigma$ is electrical conductivity, $d$ is lamination thickness, $\rho$ is mass density of the material, $S$ is cross section of the lamination, $G$ is a constant and $V_{0}$ is also a constant which depends on the micro structure of the material.

As given in Equations (3)-(8), core losses directly depend on the physical and electromagnetic features of the core material, as well as frequency and core induction. Therefore, selecting superior core grades which have lower specific losses and lower thicknesses, is the main solution to reduce core losses in the design stage of transformers.

\section{Electrical design studies}

Eleven different steel types in three different grades were investigated in electrical design stage of studied transformers. Among them, M grade steels (M2, M3, M4, M5 and M6), named in AISI system, are widely preferred for the manufacturing of transformers and power reactors in industry. In this notation, $\mathrm{M}$ stands for magnetic material and the following number represents the core loss degree of that grade [23]. Comparing to $\mathrm{M}$ grades, $\mathrm{H}$ grade steels provide lower core losses and less noisy structures, by means of higher permeabilities and lower residual stresses [24]. Core losses could be reduced up to $10 \%$, using $\mathrm{H}$ grade materials [12]. Core loss characteristics of $\mathrm{H}$ grade steels are being enhanced in H-DR grades. By means of employed laser scribing process, eddy current component of no-load losses could be reduced as a result of improved domain structure of the material.

Various electrical designs of a $1250 \mathrm{kVA}, 34.5 / 0.4 \mathrm{kV}, 50 \mathrm{~Hz}$ distribution transformers were obtained for different core inductions and core materials. According to EN50588-1, maximum value of core losses of such a transformer are specified as $1092.5 \mathrm{~W}, 982.25 \mathrm{~W}$ and $552 \mathrm{~W}$ for $\mathrm{A}_{0}, \mathrm{AA}_{0}$ and $\mathrm{AAA}_{0}$ loss classes, respectively. In addition, maximum value of load losses is specified as $10450 \mathrm{~W}$ for $\mathrm{A}_{\mathrm{k}}$ class and short circuit impedance is given as $6 \%$ [25].

Defining the cross-section area of the core is the first step of the design process. This parameter was calculated using core induction value, as given in Eq. (1). In this study, 25 different electrical designs were completed for the core inductions between $0.25 \mathrm{~T}$ and $1.90 \mathrm{~T}$. In each design, stacking factors of core materials, obtained from [24],[26], were also considered in the calculation of effective core cross section. Winding design for both primary and secondary windings were also studied to match the short circuit impedance value, given in EN50588-1. 
In all designs, calculated load losses were below the maximum limit value of $A_{k}$ class. Depending on the calculated diameters of primary and secondary windings, core window dimensions were optimized. Resulting weight of core materials were calculated by means of these optimized designs and considered in the calculation of total material costs.

By means of the obtained design parameters of these 25 electrical designs, making a comparison among the effectiveness of different core grades have been possible. M5 steel, which have a thickness of $0.30 \mathrm{~mm}$, is currently the most widely preferred core material in manufacturing of transformer and power reactors. Obtained results for M5 steel show that the limit values of no-load losses for $\mathrm{A}_{0}, \mathrm{AA}_{0}$ and $\mathrm{AAA}$ classes have been obtained for core inductions of 1.31T, 1.10T and $0.40 \mathrm{~T}$, respectively. M2 steel, which have a thickness of $0.18 \mathrm{~mm}$, gives the best results among $\mathrm{M}$ grades. Using this material, core inductions were calculated as $1.58 \mathrm{~T}, 1.50 \mathrm{~T}$ and $0.68 \mathrm{~T}$, to meet the limits of loss classes expressed above, respectively. Increased induction values provide more compact core designs and decrease material cost of the core. However, M6 steel, which is the thickest lamination among M grades, causes larger core designs. As a result of that, core induction should be decreased below $0.25 \mathrm{~T}$, to obtain the suitable core design of AAA 0 loss class.

Obtained results of electrical designs for $\mathrm{H}$ grade materials, prove the advantages of these grades, compared to $\mathrm{M}$ grades. By using $0.23 \mathrm{~mm}$ thick $\mathrm{H} 0$ steel, which is the best type of that grade, required core inductions were calculated as $1.7 \mathrm{~T}, 1.62 \mathrm{~T}$ and $0.7 \mathrm{~T}$, to match the necessities of $\mathrm{A}_{0}, \mathrm{AA}_{0}$ and $\mathrm{AAA}_{0}$ loss classes, respectively. For $\mathrm{H} 2$ steel, which has the same thickness of M5, these induction values were obtained as $1.57 \mathrm{~T}, 1.42 \mathrm{~T}$ and $0.5 \mathrm{~T}$ for the loss classes expressed above, respectively.

Choosing of H-DR grade materials, which domain structure was improved by laser scribing process, resulted with more compact transformer designs. The better steel type among this grade is $0.23 \mathrm{~mm}$ thick H0-DR steel, which have the same thickness with H0 steel. Selecting H0-DR steel for core design, core inductions were calculated as $1.74 \mathrm{~T}, 1.67 \mathrm{~T}$ and $0.78 \mathrm{~T}$, to match the necessities of $\mathrm{A}_{0}, \mathrm{AA}_{0}$ and $\mathrm{AAA}_{0}$ loss classes, respectively.

Calculated core losses vs. core induction curves for studied M, $\mathrm{H}$ and $\mathrm{H}-\mathrm{DR}$ grades, are given in Figure 1-3, respectively. Limit loss values of $A_{0}, A_{0}$ and $A_{A A}$ loss classes are also given in figures for comparison.

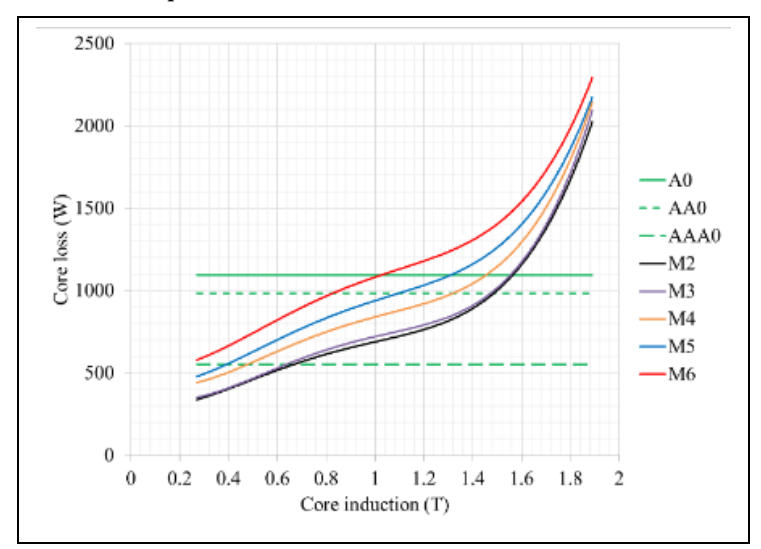

Figure 1: Core loss vs. core induction curves of designed M grade cores.

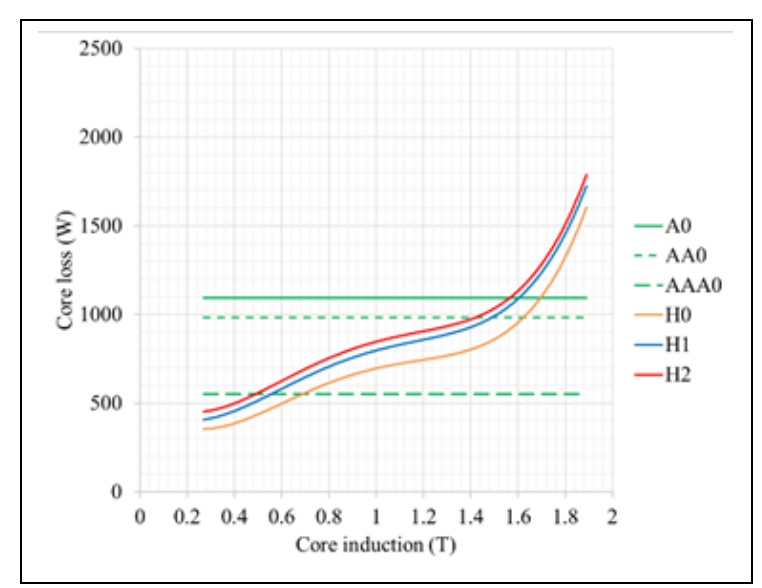

Figure 2: Core loss vs. core induction curves of designed $\mathrm{H}$ grade cores.

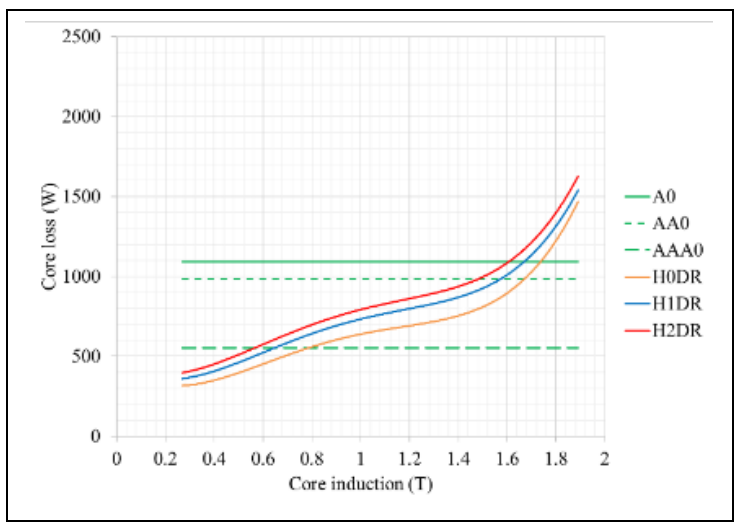

Figure 3: Core loss vs. core induction curves of designed H-DR grade cores.

\section{Verification of electrical design process}

One of the completed electrical designs, which has the core induction of $1.2 \mathrm{~T}$ and matches with the necessities of $\mathrm{AA}_{0} \mathrm{~A}_{\mathrm{k}}$ class, was selected for the verification of the design study. H0-DR grain-oriented steel was used as core grade. Primary and secondary windings were copper conductors.

Both simulations and experimental studies have been carried out to define no-load and load losses of the prototype transformer. Electromagnetic analyses were performed using ANSYS Maxwell3D v16.1 software. As results of simulation studies, no-load losses, load losses and short circuit reactance values were obtained. These results were verified with the corresponding values of $\mathrm{AA}_{0} \mathrm{~A}_{\mathrm{k}}$ class transformer limits, given in EN50588-1. Core induction was also obtained and checked with the electrical design parameter.

Flux density distribution of the simulated core is given in Figure 4.

Experimental studies were also realized to verify the simulation results and finite element model. View of the active part of the prototype transformer is given in Figure 5. No-load and load tests were realized at test laboratory of the manufacturer, according to the requirements of IEC 60076-1 [27]. All measurements were obtained with an a-eberle PQ-Box 200 Mobile Energy Analyzer. 


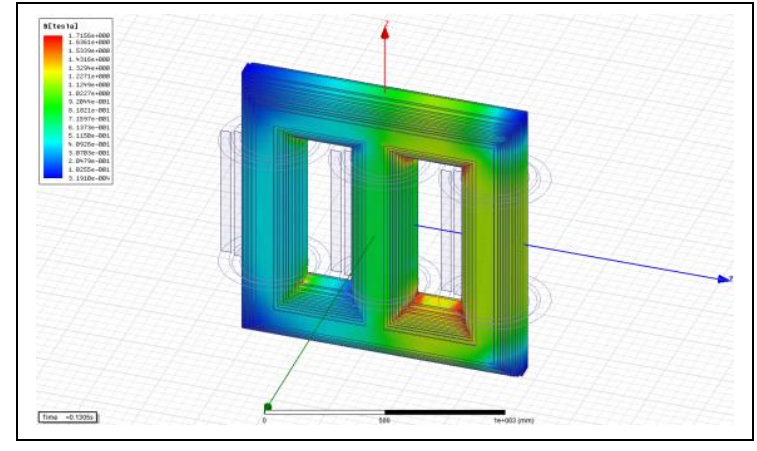

Figure 4: Flux density distribution on designed core.

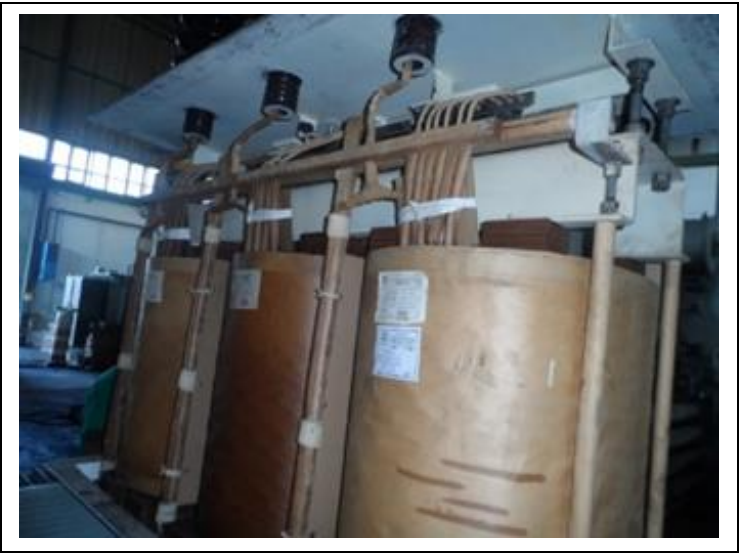

Figure 5: View of the active part of the prototype transformer.

Measured losses in laboratory tests are given in Table 1, in comparison with both design and simulation results.

Table 1: Comparison of no-load and load losses of prototype transformer.

\begin{tabular}{lcc}
\hline & $\begin{array}{c}\text { No-load loss } \\
\text { (W) }\end{array}$ & $\begin{array}{c}\text { Load loss } \\
(\mathrm{W})\end{array}$ \\
\hline Analytical design & 697 & 9590 \\
Simulation results & 680 & 10547 \\
Measurement results & 706 & 9712 \\
\hline
\end{tabular}

\section{Cost analysis}

Total manufacturing cost TMC of a transformer is expressed as;

$$
T M C=M C+L C
$$

Where; $M C$ is the total material cost and $L C$ is the labor cost of manufacturing process. Total material cost is also given as;

$$
M C=C_{\text {winding }}+C_{\text {core }}+C_{\text {tank }}+C_{\text {ins }}+C_{\text {corr }}+C_{\text {oil }}+C_{\text {add }}
$$

Components on the right-hand side of this equation are the costs of winding material, core material, tank material insulator material, corrugated panel, oil (for oil-immersed transformers) and additional costs, such as bushings, core clamps etc., respectively.

Total weight of winding material mainly depends on the diameter of core leg. Considering the cross section of core leg increases with the decrease of core induction, required winding material would also be increased in such as electrical design. Required amount of insulating materials are increased in parallel with the winding dimensions. Similarly, required amount of the materials of transformer tank and corrugated panels are also mainly depend on the transformer dimensions.
Due to the transformer tank should be strong enough mechanically, thickness of tank walls should be increased depending on the total weight of transformer. So, total weight of the tank material not only increases with the physical dimensions of the active part of transformer but also depend on the thickness of tank walls. Total required amount of insulation oil is increased with the tank volume. Additional costs of materials are also increased with the dimensions of the active part of transformer, except the cost of accessories such as bushings, thermometers, pressure valves etc. In addition, labour cost, given in Equation (9), is accepted as about 10\% of total material cost of transformer.

Considering these issues, costs of all the components of the right side of Equation (10) mainly depend on the core dimensions which are inversely proportional with core induction. Increasing transformer dimensions also increase total manufacturing cost. In this paper, only core material costs are investigated. Other material costs, expressed in Equation (10), are neglected.

Core material cost is simply calculated as;

$$
C_{\text {core }}=W_{\text {core }} P_{\text {steel }}
$$

depending on the electrical design of the core. In this equation; $W_{\text {core }}$ and $P_{\text {steel }}$ are the weight of core material $(\mathrm{kg})$ and unit cost of core material (USD $/ \mathrm{kg}$ ), respectively,

In Figure 6, weight of core material vs. core induction, is given in pu. Weight of the core for the design study of $1.31 \mathrm{~T}$, which is the core induction value of $A_{0}$ class core design with M5 steel, is accepted as reference design. Depending on the decrease of core induction, increase in core dimensions cause parabolically increase of core weight.

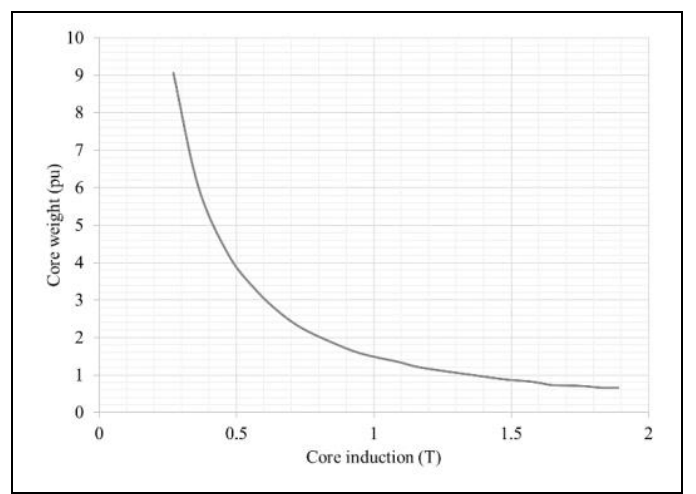

Figure 6: Core weight vs. core induction curve in pu.

Core material costs of various electrical designs for different materials and loss classes were calculated using Equation (11). Average specific costs of $\mathrm{M}, \mathrm{H}$ and $\mathrm{H}-\mathrm{DR}$ grades were considered as $2.6 \mathrm{USD} / \mathrm{kg}, 3.1 \mathrm{USD} / \mathrm{kg}$ and $3.6 \mathrm{USD} / \mathrm{kg}$, respectively. Calculated costs of core grades are given in p.u. for $\mathrm{A}_{0}, \mathrm{AA}_{0}$ and $\mathrm{AAA}_{0}$ class designs, respectively.

Figure 7 shows the core material costs of various steels, which match the requirement of core loss for $A_{0}$ class. M4 steel provides the most economical design for that class. Minimum costs for $\mathrm{H}$ and $\mathrm{H}-\mathrm{DR}$ grades are calculated as 1.136 and 1.230 times of the cost of M4 core.

Similarly, M4 steel also provides the minimum core cost for $\mathrm{AA}_{0}$ class designs. Calculated core cost for this class is given in Figure 8. Minimum cost for $\mathrm{H}$ and $\mathrm{H}-\mathrm{DR}$ grades are calculated as 1.143 and 1.229 times of the cost of M4 core. 


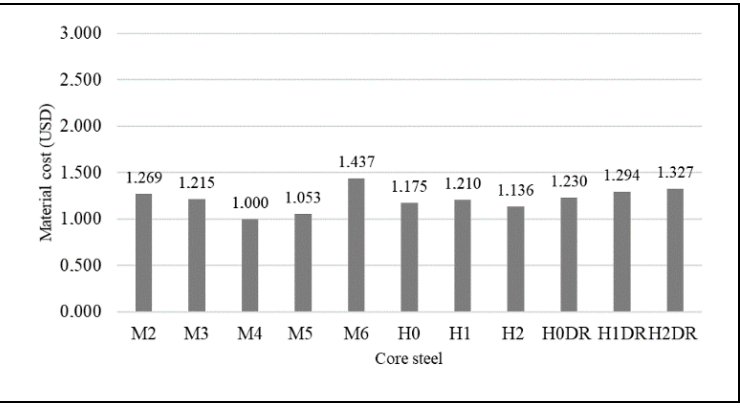

Figure 7: Costs of core grades for $\mathrm{A}_{0}$ class cores.

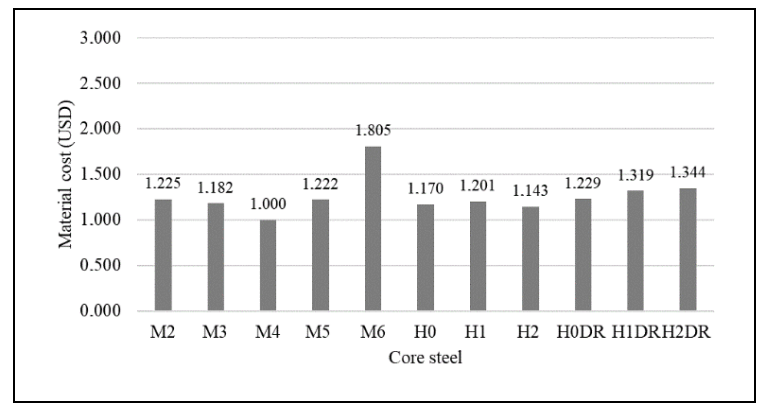

Figure 8: Costs of core grades for $\mathrm{AA}_{0}$ class cores.

Electrical design studies prove that, core induction should be greatly decreased to match the requirements of $\mathrm{AAA}_{0}$ class, using Si-Fe core grades. Such designs result with the great physical dimensions of the active parts of transformers and increase total weight of core. For $\mathrm{AAA}_{0}$ class designs, M2 and H0-DR steels provide the minimum core costs, as given in Figure 9. However, calculated core weights show that, 15.7\% less material is required and therefore more compact core design would be succeeded, preferring H0-DR steel material.

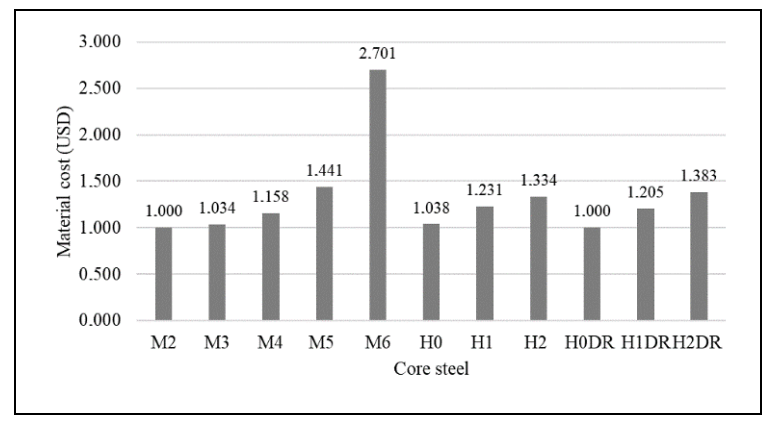

Figure 9: Costs of core grades for AAA0 class cores.

\section{Conclusion}

EN50588-1 regulation brought strict limits for the power losses of distribution transformers. Depending on these necessities, transformer manufacturers need to improve the electrical designs of their products. However, manufacturing costs are as important factors as the performance and efficiency for transformer manufacturers.

In this study, feasibility of the electrical designs of distribution transformers for various $\mathrm{Si}-\mathrm{Fe}$ core grades, matching the necessities of EN50588-1, are investigated.

Twenty-five different electrical designs, for 11 different steel types each, were investigated in this study. Design results prove that, manufacturing of transformer cores in all three loss classes, are technically possible using $\mathrm{Si}-\mathrm{Fe}$ core grades. Obtained results show that, considering the current specific costs of core grades, M2 steel provides the most economic core designs for all no-load loss classes of EN50588-1. Only for AAA0 class, H0-DR steel gives equal cost for core manufacturing.

Obtained results of this study make the evaluation of calculated design and cost values possible in both technical and economical manner.

According to the results, design and manufacturing of $A_{0}$ class transformers are easily possible and feasible by selecting conventional $\mathrm{M}$ grade $\mathrm{Si}-\mathrm{Fe}$ materials and multistep-las core construction method. Despite the design and manufacturing are also possible with $\mathrm{M}$ grades, considering the compactness of transformer core and closeness of core manufacturing cost with $\mathrm{M}$ grades, $\mathrm{H}$ and $\mathrm{H}-\mathrm{DR}$ grades could be good alternatives to be considered to match the $\mathrm{AA}_{0}$ class necessities. However, considering either total weights or material costs, manufacturing of $\mathrm{AAA}_{0}$ class transformers are not feasible by selecting Si-Fe grades. These class only seems to be feasible by using amorphous materials and wound core construction.

\section{Acknowledgement}

The author would like to thank Sönmez Transformer for their contribution to the experimental stage of this study.

\section{References}

[1] Georgilakis PS. "Differential evolution solution to transformer no-load loss reduction problem". IET Generation, Transmission \& Distribution, 3(10), 960-969, 2009.

[2] Haidar AMA, Al-Dabbagh M. "The influences of T-joint core design on no-load losses in transformers". IEEE Potentials, 32(3), 40-48, 2013.

[3] Binns DF, Crompton AB, Jabensari A. "Economic design of a $50 \mathrm{kVA}$ distribution transformer Part 2: Effect of different core steels and loss capitalisations". IEE Proceedings, 133(7), 451-456, 1986.

[4] Nakamura M, Hirose K, Iuchi T, Yamaguchi S, Ohya Y. "Characteristics of laser irradiated grain oriented silicon steel”. IEEE Transactions on Magnetics, 18(6), 1508-1510, 1982.

[5] Ponnaluri SV, Cherukuri R, Molian PA. "Core loss reduction in grain-oriented silicon steels by excimer laser scribing Part I: experimental work". Journal of Materials Processing Technology, 112, 199-204, 2001.

[6] Ng HW, Hasegawa R. Lee AC. Lowdermilk LA. "Amorphous alloy core distribution transformers". Proceedings of the IEEE, 79(11), 1608-1623, 1991.

[7] Najgebauer M, Chwastek K, Szczyglowski J. "Energy efficient distribution transformers". Przeglad Elektrotechniczny, 87(2), 111-114, 2011.

[8] Targosz R. "The Potential for Global Energy Savings From High Efficiency Distribution Transformers". European Copper Institute, Brussels, Belgium, Technical Report, 2005.

[9] Işık F, Uyaroğlu Y. "Amorphous core transformers efficiency analysis in Turkish electrical distribution system". Turkish Journal of Electrical Engineering \& Computer Sciences, 23(6), 1523-1535, 2015.

[10] Kurita N, Nishimizu A, Kobayashi C, Tanaka Y, Yamagishi A, Ogi M, Takahashi K, Kuwabara M. "Magnetic properties of simultaneously excited amorphous and silicon steel hybrid cores for higher efficiency distribution transformers". IEEE Transactions on Magnetics, 54(11), 1-4, 2018. 
[11] Freitag C, Leibfried T. "Mixed core design for power transformers to reduce core losses". International Aegean Conference on Electrical Machines and Power Electronics, Brasov, Romania, 25-27 May 2017.

[12] Adame SM, Vazquez EM, Galvan JCO, Perez RE. "Loss reduction by combining electrical steels in the core of power transformers". International Transactions on Electrical Energy Systems, 26(8), 1737-1751, 2016.

[13] Adame SM, Kefalas TD, Martinez SG, Rojas CP. "Electromagnetic finite element analysis of electrical steels combination in lamination core steps of singlephase distribution transformers". IEEE International Autumn Meeting on Power, Electronics and Computing, Ixtapa, Mexico, 8-10 November 2017.

[14] Kefalas TD, Kladas AG. "Reduction of cost and losses of transformers by using composite magnetic cores". International Conference on Electrical Machines, Berlin, Germany, 2-5 September 2014.

[15] Upadhyay G, Singh A. "FEM based No-load Loss Calculation of Triangular Wound Core Transformer". IEEE International Conference on Power Electronics, Intelligent Control and Energy Systems, Delhi, India, 4-6 July 2016.

[16] Kefalas TD, Kladas AG. "Development of distribution transformers assembled of composite wound cores". IEEE Transactions on Magnetics, 48(2), 775-778, 2012.

[17] Kefalas TD, Kladas AG. "Mixed Si-Fe wound cores five legged transformer: losses and flux distribution analysis". IEEE Transactions on Magnetics, 48(4), 1609-1612, 2012.

[18] Cinar MA, Alboyaci B, Sengul M. "Comparison of power loss and magnetic flux distribution in octagonal wound transformer core configurations". Journal of Electrical Engineering and Technology, 9(4), 1290-1295, 2014.
[19] Pfützner H, Shilyashki G, Hamberger P, Aigner M, Hofbauer F, Palkovits M, Trenner G, Gerstbuer E, Matkovic I, Galaboy V. "Automatic 3-D building factor analyses of a grain-oriented model transformer core". IEEE Transactions on Magnetics, 50(4), 1-4, 2014.

[20] Popescu M, Miller TJE, McGilp M, Ionel DM, Dellinger SJ, Heidemann RJ. "On the physical basis of power losses in laminated steel and minimum-effort modeling in an industrial design environment". IEEE Industry Applications Annual Meeting, Louisiana, USA, 23-27 September 2007.

[21] Broddefalk A, Lindenmo M. "Dependence of the power losses of a non-oriented 3\% Si-steel on frequency and gauge". Journal of Magnetism and Magnetic Materials, 304(2), 586-588, 2006.

[22] Mthombeni TL, Pillay P. "Physical basis for the variation of lamination core loss coefficients as a function of frequency and flux density". 32nd IEEE Annual Conference on Industrial Electronics, Paris, France, 6-10 November 2006.

[23] AK Steel. "Selection of Electrical Steels for Magnetic Cores, Product Data Bulletin". Ohio, USA, 1, 2007.

[24] AK Steel. "TRAN-COR H Grain Oriented Electrical Steels, Product Data Bulletin". Ohio, USA, 1, 2013.

[25] CENELEC. "EN50588-1 Medium Power Transformers $50 \mathrm{~Hz}$ with Highest Voltage for Equipment not Exceeding $36 \mathrm{kV}$-Part 1: General Equipments, International Standard". Brussels, Belgium, 2015.

[26] AK Steel. "CARLITE Grain Oriented Electrical Steels, Product Data Bulletin". Ohio, USA, 1, 2013.

[27] CENELEC. "EN60076-1 Power Transformers-Part 1: General, International Standard”. Brussels, Belgium, 2011. 